\title{
Museu virtual (e plural) de arte
}

\author{
ANA BEATRIZ BAHIA
}

\section{Resumo}

O artigo aborda os museus virtuais de arte, interfaces online que essas instituições desenvolvem para ampliar a comunicação com seus públicos. Evoca o conceito de museu plural proposto por Martín-Barbero e discute iniciativas em três tipos de interface: bancos de dados, visitas virtuais e jogos digitais. Analisa a relação obra-espectador que se dá em cada iniciativa, enfocando jogos de três museus: Tate Gallery de Londres, Museu Boijmans de Roterdan e Museu Virtual de Arte Brasileira. Conclui que o emprego de tecnologias não

Palavras-chave: Museu virtual, obra de arte, Martín-Barbero é condição, sequer garantia, para realização do conceito de museu plural, o que depende de como o museu entende seu papel institucional e relaciona-se com seus públicos. 


\title{
Virtual (and plural) Art Museum
}

\author{
ANA BEATRIZ BAHIA
}

\begin{abstract}
This paper is about virtual museums of art, which are web interfaces developed by museums to interact with their audiences. It is based on the "plural museum", a concept proposed by Martin-Barbero, and presents three kinds of interfaces: databases, virtual tours, and digital games. It analyzes the relation between artwork and audience in each interface, then it focuses on digital games of three museums: Tate Gallery in London, Museum Boijmans of Rotterdam, and Virtual Museum of Brazilian Art. It concludes that the use of technology is not necessary nor a guarantee of a "plural museum”, as it depends on how the museum understands its own institutional role and relates to its audiences.
\end{abstract}

Key words:

Virtual museum, artwork, Martín-Barbero 


\title{
Museo virtual (y plural) de arte
}

\author{
ANA BEATRIZ BAHIA
}

\section{Resumen}

Este artículo aborda los museos virtuales de arte, interfaces online que esas instituciones desarrollan para ampliar la comunicación con sus públicos. Se evoca el concepto de museo plural propuesto por Martín-Barbero y que discute iniciativas en tres tipos de interface: bancos de datos, visitas virtuales y juegos digitales. Se analiza la relación obraespectador que ocurre en cada iniciativa, enfocando juegos de tres museos: Tate Gallery de Londres, Museum Boijmans de Róterdam y el Museu Virtual de Arte Brasileira. Finalmente, se concluye que el empleo de tecnologías no es una condición, ni

Palabras clave: Museo virtual, obra de arte, Martín-Barbero siquiera una garantía, para la ejecución del concepto de museo plural, el cual depende de las formas como el museo entienda su papel institucional y se relacione con sus públicos. 
A arte é uma ficção histórica, como já provou Marcel Duchamp, do mesmo modo que a história da arte, o que André Malraux descobriu sem querer quando escreveu o "museu sem paredes". Portanto, é uma questão de instituições e não de conteúdo, e muito menos de método, se e como arte e história da arte sobreviverão no futuro.

(Hans Belting, O Fim da História da Arte)

Mediação em museus de arte é um tópico complexo. Para abordá-lo, há de se tomar o Museu enquanto instituição social, entidade que tanto faz perdurar valores e hábitos culturais quanto, ao explicitar as relações de poder implícitas a tais práticas, propicia gradual renovação. No caso dos museus de arte, por um lado, a ação museal reafirma os modos de perceber, fazer e saber arte já legitimados, por outro lado, ao provocar incômodo e despertar novas ideias, impele à transformação da própria arte. Mesmo assim, a coerência do discurso museal nos permite encarar o museu como local de certezas, espaço de densidade antropológica, ajudando-nos a suportar a consciência da finitude. Como bem escreveu Mário Chagas (2005), museu é espaço de enfrentamento da morte.

Pensar desde aí instiga-nos a não encarar a tradição artística de forma tradicionalista, mas como algo que sempre está em construção. É ainda deslocar o eixo da comunicação museal do assunto (a obra) para as experiências de cada visitante e os processos de significação vividos nesse contexto institucional. É compactuar com a ideia de museu plural.

\section{Museu plural}

Museu plural foi o termo escolhido por Jesús Martín-Barbero (2000) para propor um tipo de atuação de museus que não 
leve à pasteurização do patrimônio cultural. Martín-Barbero é conhecido por suas pesquisas sobre processos de significação de mensagens televisivas. A partir desses processos ele pensa a mediação em museus, reconhecendo perdas e danos decorrentes da comunicação massiva. Porém, não nos deixemos iludir pelo senso comum: comunicação massiva, conforme é diagnosticada por Mantín-Barbero, não é causada por equipamentos de áudio e vídeo usados nas salas expositivas do museu; antes, é decorrência de paradigmas constitutivos do museu moderno sob o ideal de "democratização do saber". Cabe aos museus, além de oferecer acesso aos bens culturais, diversificar as formas de comunicação desses bens, usando estratégias indutoras de participação efetiva da comunidade nos processos de significação do patrimônio e da própria instituição museal. E, vale dizer, os equipamentos de áudio e vídeo, quando bem empregados, contribuem para tanto.

Mantín-Barbero traçou três premissas para que se estabeleça comunicação plural entre museu e seus públicos. Primeiro, o autor solicita que o museu des-neutralize seus discursos, trazendo à tona o aspecto ambíguo das tradições e problematizando o poder dos discursos institucionais. Segundo, que não se apresente como "caixa-forte da tradição", mas como espaço de encontro e de diálogo sobre memórias. O que temos, então, é um museu des-locado, fora do "centro" (fonte da verdade) acerca da tradição. Por fim, a terceira premissa do museu plural reafirma as duas primeiras e avança no sentido prático. Aponta para um museu des-limitado, que se deixa interpelar pelo turismo cultural e que é parceiro de organizações não governamentais, só para citar duas estratégias nessa linha. Trata-se de um museu sem fronteiras, disposto a reinventar não apenas seus métodos, mas sua posição na sociedade e seu espaço de atuação, sempre visando melhor dialogar com seus públicos.

A ideia de um museu des-limitado ecoa na reflexão que o próprio Martín-Barbero (2004) tece em parceria com Germán Rey que trata da atual condição instável das instituições de legitimação do saber - como é o caso do museu. Segundo eles, isto se deu desde o advento da televisão e, principalmente, do computador. Mas eles encaram tal instabilidade de forma positiva, como algo que impele à salutar atualização das práticas institucionais. Daí apontarem necessidade de incorporação da tecnologia não apenas em sua dimensão técnica, mas comunicacional, utilizando-a para promover modos plurais de ver, de saber e, principalmente, de conviver. São incontáveis as possi- 
bilidades de uso que estão por fazer, pois os museus somente começaram a se apropriar das tecnologias computacionais.

Vale dizer que não são apenas as práticas museais que se transformam com o uso de recursos tecnológicos. O contrário também se dá. Os sentidos que entrevemos em dada tecnologia devem-se menos a sua origem e mais aos modos de uso - ou de desuso - que dela fazemos. Portanto, o fato de a Internet e os jogos digitais terem sido desenvolvidos em contexto de guerra não nos impede de tomá-los hoje com finalidade cultural, artística, educacional. É isso que museus de arte de várias partes do mundo vêm fazendo, construindo museus virtuais e mídias interativas (hipermídias) para diversificar e aprofundar a comunicação com seus públicos. Esse constructo tanto proporciona novos modos de estar num museu e de conhecer obras de arte, quanto torna mais complexo e humano o sentido que o computador tem em nossas vidas.

\section{Museu virtual}

A extensão web criada por um museu costuma ser nomeada "museu virtual". Sem entrar no mérito da escolha do termo virtual - o que nos reportaria ao conceito de Potência, discutido a partir da Metafísica de Aristóteles -, é sabido que um museu virtual é muito mais que um folder eletrônico, não se limita a veicular informações sobre as atividades realizadas no espaço tangível do museu. Museu virtual é espaço de atuação museal, realizando estratégias de comunicação tão efetivas - e diferenciais - como aquelas praticadas e legitimadas nos museus-prédio.

Como detalhei anteriormente (BAHIA, 2007; 2008), os primeiros museus virtuais foram lançados quase simultaneamente com a própria $W e b$, no início da década de 1990. Logo despertaram maior interesse público, aqueles que ofereciam visita virtual, ou seja, hipermídia produzida a partir de fotos panorâmicas da parte interna do museu e que permitem ao visitante perceber-se no centro de cada sala expositiva e alterar a direção do seu olhar em até $360^{\circ}$. Este tipo de hipermídia continua em voga até hoje, agora desenvolvida com alto grau de realismo, algo que os softwares 3D e as imagens de alta resolução permitem, como podemos conferir visitando o MUVA - Museo Virtual de Artes El Pais (http://muva.elpais.com.uy). O exemplo citado é um museu virtual criado para reunir obras de artistas uruguaios que estão em coleções públicas e privadas, espalhadas pelo mundo. Apesar da intenção arrojada, a forma do MUVA é bastante con- 
vencional; replica a estrutura de salas expositivas mesmo não existindo um museu tangível a ele correspondente.

A visita virtual é um tipo de interface interessante para quem planeja ir a um museu-prédio, especialmente àqueles de grande porte e vasto acervo. Contudo, não costuma ser bom recurso para quem quer olhar uma obra em pormenor ou obter informações específicas sobre ela. Exemplo está no site do Museu do Louvre (http://www.louvre.fr), no qual a visita virtual permite percorrer sala após sala do museu, perceber detalhes do piso de madeira e localizar os bancos de descanso. Mas, diferindo do MUVA, as panorâmicas da visita virtual do Louvre são de baixa resolução e as obras aparecem excessivamente diminutas. A Mona Lisa, por exemplo, é vista em tamanho de $12 \times 14$ pixels - enquanto a dimensão total da tela de computador dos usuários costuma ser de 1280 x 720 pixels, ou mais -, ficando difícil até mesmo reconhecê-la como retrato de uma senhora. Numa outra parte do site do Louvre é possível ver a Mona Lisa em detalhe. Trata-se do banco de dados que contem reproduções em alta resolução e informações básicas de 30.000 peças do acervo. Há motor com filtros de busca, permitindo que o visitante construa rotas de exploração desse acervo, diferentes daquelas que a visita ao museu-prédio proporciona. Também há recurso para acessar simultaneamente, e na mesma tela, os dados de duas obras distintas, facilitando o estudo comparativo. Lamentável que a interface da visita virtual não esteja integrada a do banco de dados no site do museu do Louvre. Seria ótimo ter ali a possibilidade que se tem no MUVA: estar na visita virtual e, ao clicar sobre a imagem de uma obra, acessar aos dados dessa obra arquivados no banco de dados.

As interfaces de visita virtual e banco de dados são recorrentes nos sites de museus de arte. Por meio desse tipo de interface on-line, os museus acabam explorando pouco a dimensão comunicacional das tecnologias digitais. Apesar de desenvolvidas com ferramentas computacionais, tais interfaces estão fundadas em modos de perceber e saber arte advindos de tecnologias intelectuais modernas - como as exposições em museus-prédio e os catálogos de arte. Isso porque a interface de um objeto computacional não é algo apenas superficial: é estrutural. Interface é o que orquestra a relação construída entre usuário e objeto computacional e com os conteúdos acessíveis a partir deste. Interface é ponto de encontro entre tecnologia e códigos culturais. Lev Manovich 
(2006) chega a defender que a informática não trouxe ruptura, ou choque cultural, pois os objetos computacionais, apesar de aportarem inovação, não rompem com os hábitos culturais pré-existentes, apenas os transcodificam ${ }^{1}$.

Interface é dupla pele que confere estilo aos objetos computacionais. Uma pele é informatizada, a outra é cultural, sendo que esta preserva categorias e conceitos - modos de estruturar informações, como são os arquivos, as exposições, os debates públicos, entre outros - estabelecidos muito antes do advento dos computadores. A pele cultural é o que torna as interfaces computacionais "amigáveis" ao público não especializado em informática, de modo que tem sido determinante para a tão rápida incorporação tecnológica em nossa sociedade. Com essas duas peles os objetos computacionais nos possibilitam viver situações familiares de um modo incontestavelmente novo. Isso explica a sensação que temos em uma visita virtual: tanto temos clareza sobre como viver aquela experiência (sabemos que devemos transitar de uma sala a outra, buscar entender o que caracteriza cada sala e cada zona do museu) quanto nos percebemos inseridos na era high-tech.

Ainda, a visita virtual simula o modo de estar no museu-prédio. Isso não se deve apenas a verossimilhança entre o visual da hipermídia e as salas do museu-prédio. Como afirma Lev Manovich (2006), há dois outros aspectos que melhor definem simulação. Primeiro, a simulação mostra-se sempre como continuidade do contexto no qual ela é apresentada. É por esse motivo que as visitas virtuais costumam ser a parte dos sites de museu de arte onde nos sentimos mais próximos do museu-prédio, em uma experiência mais “real". Segundo, a simulação propicia uma experiência de imersão, o que significa agir dentro de um sistema (computacional) que tem como referência outro sistema, mais complexo, que é a própria realidade referente. Assim, além de mimetizar a aparência das coisas, enquanto simulação (FRASCA, 2015), a visita virtual plasma modelos comportamentais oriundos da visita às salas expositivas do museu-prédio.

No MUVA, devido à integração da visita virtual com o banco de dados, o comportamento modelado mescla o espectador-contemplador com o estudioso da arte. Já no Louvre, a própria posição de espectador é abreviada. Devido às limitações de aproximação da imagem, a lei do "não é permitindo tocar" contamina o museu virtual. Reafirma um conceito de museu pautado na "pedagogia de olhar a arte", no qual "os olhos e as mentes são 
bem-vindos, mas o corpo não" (FREIRE, 1999, p. 43). O problema é que, ao não conseguir se aproximar da obra, o espectador acaba não sendo "tocado" pela imagem (BAHIA, 2008).

\section{Interfaces plurais em museus virtuais de arte}

Para além das visitas virtuais e dos bancos de dados, os museus de arte vêm experimentando formas diferenciais de dialogar com seus públicos. Lançam projetos que podem se estender do museu-prédio à sede virtual, por vezes deixando-se permear por instituições parceiras. Assim, fazem ecoar a ideia de museu des-limitado, de Martín-Barbero.

Exemplo é o projeto que a National Gallery de Londres (http://www.nationalgallery.org.uk) realiza em parceria com a Universidade Saint Martin ea Escola de Cinema, também de Londres. Os alunos destas instituições produzem mídias (animações evídeos de curta-metragem) que se apresentam como metatextos de obras do acervo, já que não falam sobre obras do acervo, mas a partir delas. Por fim, as mídias são publicadas no site da National Gallery, em seção específica sobre este projeto, e incorporadas à nuvem de informações on-line que circunda a coleção.

O projeto citado reafirma a ideia de museu des-limitado, não apenas por seu caráter interinstitucional, mas por não compactuar com certos paradigmas constitutivos dos museus modernos - como a valoração da obra de arte enquanto objeto genuíno, completo em si mesmo, e a supremacia da contemplação como modo de conhecer uma obra. Cada mídia produzida é resultado de uma leitura de fruição ${ }^{2}$ (BARTHES, 1996) da obra vivenciada pelo aluno, de modo que exterioriza a posição coautoral do espectador contemporâneo.

Esse não é o único exemplo de interface promotora de atuação coautoral do espectador (BARTHES, 2004). No Museu experimental, interface vinculada ao MAC Virtual (http://www. macvirtual.usp.br) do Museu de Arte Contemporânea da Universidade de São Paulo, o visitante pode atuar como curador de exposição on-line, deixando sua produção para ser vista por outros visitantes. Em outros museus virtuais, o visitante pode propor círculos de discussão que congreguem interessados em arte de várias partes do mundo. Exemplo disso é o diretório de comunidades virtuais Espacio abierto, vinculado ao portal educacional do Museu Thyssen-Bornemisza de Madri (http:// www.educathyssen.org). 
É amplo o leque de exemplos que podem ser citados aqui. Contudo, opto por destacar o gênero de interface sobre o qual me dedico a pesquisar: jogos digitais (também denominados games) concebidos a partir de obras de arte (BAHIA, 2008; 2014).

Não interessa aqui abordar os jogos digitais nos quais a reprodução da obra de arte paira na superfície gráfica da interface, como ocorre em jogos da memória e em quebra-cabeças apresentados isoladamente nos quais não existe nexo algum entre a estrutura do jogo e as obras nele citadas, ou seja, caso substituíssemos as obras a jogabilidade não seria comprometida. Sabemos que não é por "interagir" (clicando sobre coisas num ambiente digital) que o visitante museal participa do infindável processo de significação da obra. De fato, é viável jogar certos jogos digitais disponíveis na web sem sequer olhar para a imagem artística neles citada.

Vale despender atenção aos jogos digitais cuja interface foi concebida a partir de uma dada obra, ou de um conjunto de obras. Nesses, a interface incorpora especificidades semânticas e/ou formais da/s obra/s, apresentando-se enquanto metatexto de obra. Tais jogos não desempenham a função de reprodução da obra; oferecem uma relação diferencial com o universo imagético da obra. Ou seja, se comparados com a experiência da contemplação, esses jogos digitais propiciam um modo mais divertido e interativo de aproximar-se da obra. Nem por isso desqualificam a experiência da contemplação. Sabemos que pessoas têm experiências efetivas com obras de arte por caminhos diversos: através de dinâmicas lúdicas e de grupo, em experiências sinestésicas e interpessoais, ou de forma intrapessoal privilegiadora do olhar. Logo, o que os museus virtuais que veiculam estes jogos digitais evidenciam é a importância de oferecer pluralidade de modos de comunicar o acervo e de promover a significação das obras entre os públicos visados.

Bons exemplos estão nas três interfaces de jogo digital apresentadas na sequência. Elas foram produzidas a partir de motivações diversas, cada qual tem uma forma própria que é coerente com seu objetivo e diferente das demais.

\section{Art Detective: The Case of the Mysterious Object}

Produzido pela Tate Gallery de Londres, Art Detective: The Case of the Mysterious Object (www.tate.org.uk/detective/ mysteriousobject.htm) é jogo no qual o espectador investiga a 
escultura Recumbent Figure, de 1938, obra do artista do modernismo europeu Henry Moore e que integra o acervo do museu.

O cenário do jogo é a própria sala expositiva do museu, mas sua interface difere da estrutura de visita virtual. O olhar do jogador não se dispersa; mantém o foco na obra. Sempre tendo a obra no centro do seu campo de visão, o jogador usa recursos interativos que lhe permitem aproximar, recuar e circundar a escultura. Tudo isso ganha sentido especial quando se considera a narrativa-guia do jogo e a missão do jogador. O jogador desempenha o papel de detetive, não de visitante do museu, e tem a responsabilidade de resolver oito casos sobre a obra do acervo. Ele só conseguirá desvendar os mistérios se usar tanto sua habilidade de observação quanto as informações ali disponíveis, as quais versam sobre os materiais de confecção, o processo de criação e o autor dessa escultura.

A interface desse jogo mantém o espectador apartado da temática da obra - uma mulher reclinada. Isso não desacredita a motivação educativa desta hipermídia. De forma muito particular, esse jogo promove reflexão de processos de abstração da forma e de pesquisa de materiais naturais vividos pelo artista. Ele evidencia o contexto modernista no qual a obra foi criada e promove o olhar analítico sobre a forma, o que não deixa de aportar uma experiência significativa com a obra.

A lógica de jogo de investigação é recorrente em jogos de museus virtuais destinados ao público juvenil, reafirmando a ideia de obra como enigma. Por um lado, a investigação aproxima esse público da arte, desperta interesse, instiga o espectador a rever - conhecer de forma diferente - o antes conhecido. Isso implica em demora do olhar, mesmo que não seja a demora contínua da contemplação, mas a recorrência de olhares lançados sobre dado objeto. Por outro lado, a investigação impõe ao espectador certo distanciamento em relação à obra. Tal distanciamento é necessário para manter o "foco" do olhar objetivo, para observar, analisar, relacionar dados e resolver os casos criados a partir daquela obra. Ou seja, é a capacidade de análise e a clareza intelectual que se destacam frente a outros sentidos e habilidades cognitivas possíveis de serem usados pelo público.

\section{Jheronimous Bosch Adventure Game}

Esse jogo também é voltado ao público juvenil, mas tem como referência os jogos de aventura RPG (Role-Playing Game). Oferece ao jogador uma experiência de imersão e promove um 
tipo de relação mais empática do que a vivida por meio do jogo Art Detective. O jogo foi feito para acompanhar a exposição com obras de Jheronimous Bosch, realizada no ano de 2000 no Museu Boijmans Van Beuningen, de Roterdan. Um ano antes do início da mostra, o museu convidou o grupo de artistas do V2_Lab para desenvolver uma interface on-line com obras da exposição e que fosse atrativa ao público jovem. Isso porque o museu havia constatado a perda de interesse das novas gerações em relação ao museu. Os artistas do V2_Lab estavam certos de que a interface de visita virtual não atrairia jovens desmotivados a ir ao museu-prédio, por isso propuseram desenvolver um jogo digital. A ideia foi abraçada por Chris Will, coordenador do setor educativo do museu na época, e por sua equipe, sendo posteriormente encarada pela instituição como referência de iniciativa bem sucedida.

Todo o conteúdo de Bosch Adventure Game - da estrutura ao layout - foi concebido a partir das obras de Bosch. Os cenários e personagens foram feitos "recortando" e remontando, em meio digital, fragmentos de pinturas do artista. $\mathrm{O}$ mundo do jogo é recriação da cidade holandesa Hertogenbosch no final do século XV, contexto histórico e geográfico em que viveu Bosch. Tal recriação traz à tona aspectos sociais daquela comunidade, como a tensão entre o imaginário medieval-pagão e o controle da ordem católica ali reinante. Isso é base do universo imagético de Bosch, por isso está presente no jogo digital (BAHIA, 2014).

O jogador depara-se com desafios espalhados nessa cidade, em locais externos e internos que ficam acessíveis na medida em que o jogador demora-se e avança no jogo. Os desafios têm como tema situações cotidianas que despertam desejos mundanos, mas precisam ser enfrentados sem confrontar a moral religiosa daquela época. Se isso não acontece, o jogador precisa redimir-se dos pecados cometidos ou não terá um bom final de jogo.

A estrutura do jogo está pautada em duas obras de Bosch: Os sete pecados capitais e $O$ mascate. A primeira é o eixo do roteiro de jogo, dos ambientes e das situações interativas. Ela é parte do acervo do Museu do Prado e traz representações dos sete Pecados Capitais em um círculo. Os pecados são mostrados em situações corriqueiras daquela época (por exemplo, dois bêbados brigando, para abordar a ira; e uma freira acordando o padre, para preguiça). No centro do círculo está o "olho" de Deus, com a inscrição: Cave, Cave, Dominus videt (cuidado, cuidado, o Senhor vê) — a propósito, no Bosch 
Adventure Game nada do que é feito pelo jogador escapa ao "olho", que é a inteligência artificial do sistema do jogo.

É importante saber que Bosch Adventure Game foi feito com recursos tecnológicos tão inovadores quanto os usados em jogos digitais de entretenimento do ano em que foi desenvolvido. Em 2001, o Bosch Adventure Game ficou entre os sete finalistas do prêmio Museums and Web (ICOM, UNESCO) na categoria Melhor Aplicativo Experimental, além de ter vencido em duas categorias do Europrix: Conhecimento, Descoberta e Cultura, e Prêmio de Destaque do Ano. Ao justificar a premiação, o júri argumentou que o jogo oferecia ao público maior interatividade com a obra do artista do que uma exposição tradicional consegue oferecer, dando ao espectador possibilidade de imersão no universo imaginado por Bosch. Para completar, ressaltou que a iniciativa é uma variação atualizada da obra de Bosch e desempenha, ao mesmo tempo, os papéis de hipermídia de entretenimento e educacional (V2_ARCHIVE, 2006).

É inegável que Bosch Adventure Game oferece diversão. Nem por isso é banal. A experiência de entretenimento nos distrai, traz alívio do esgotamento causado pelo esforço da existência, mas isso não implica em experiência impessoal, ou fácil de ser vivida. Paradoxalmente, a atividade que verdadeiramente nos distrai, também captura-nos por completo. Com a promessa de ofertar descanso, ela exige de nós esforço e dedicação em situações que não fazem parte de nosso cotidiano. A experiência de entretenimento demanda a tomada de atitude e, muitas vezes, a angústia de estar em risco, pondo em dúvida a nossa capacidade de enfrentar certos desafios. Nossas melhores lembranças de entretenimento costumam ser de jogos, e outros hobbies, que tanto mais nos dão prazer quanto mais nos desafiam. Vividas com intensidade, atividades de entretenimento nos fazem ser mais do que éramos, transformam o modo como significamos o mundo e, principalmente, como percebemos a nós mesmos e relacionamo-nos com o fragmento de mundo em que estamos envolvidos.

Unindo experiência significativa e entretenimento, Bosch Adventure Game tem interface que se aproxima menos dos jogos didáticos (aqueles que prometem ensinar um conteúdo) e mais dos jogos digitais comerciais (aqueles que prometem uma experiência divertida). Contudo, os conteúdos apresentados (personagens, cenários, narrativa-guia e todas as demais informações verbais, imagéticas e sonoras) e as habilidades cognitivas solicitadas ao jogador estão cuidadosamente alinhados com o objetivo do setor educativo do museu. Ainda, 
quem teve a oportunidade de jogá-lo - no período em que esteve on-line, entre 2000 e 2004 - pode atestar: ele se destacava, em relação a outros jogos digitais de sites de museu de arte, pelo nível de imersão proporcionado ao jogador. Aportava o reposicionamento do sujeito que se dirige ao museu e se relaciona com as obras. Foi o que atestou Chris Will (2006), comentando a exposição das obras de Bosch realizada no Museu Boijmans junto ao lançamento do jogo: além do jogo ter despertado o interesse do público jovem para a exposição como um todo, os jovens que iam ao museu davam especial atenção às obras citadas no jogo.

\section{A Terceira Face da Carta}

O jogo A Terceira Face da Carta proporciona um tipo de experiência diferente dos acima comentados, até mesmo por não ser voltado a uma faixa etária e sim ao público da arte em geral. É parte do projeto Museu Virtual de Arte Brasileira (MVAB) e foi concebido a partir da série fotográfica Antropologia da face gloriosa do artista brasileiro Arthur Omar.

A jogabilidade é oriunda do jogo da memória. Contudo, a tradicional estrutura do jogo foi transformada, impregnada pela dimensão subversiva das fotografias de Omar. O resultado é um jogo digital com três fases. Na primeira fase, o jogador precisa encontrar pares de imagens, como se costuma fazer no modo convencional de jogar memória. Na segunda fase, precisa encontrar trios de imagens. Já na terceira fase, o jogador segue buscando trios de imagens. Contudo, a cada lance, as cartas mudam de lugar, subvertendo a lógica do jogo: não é apenas a capacidade de memorização que dá ritmo ao jogar, mas também o acaso (BAHIA, 2008).

O acaso é tão importante no processo artístico de Omar quanto à ordem. Isso está posto não apenas na estrutura desse jogo digital, mas nos conteúdos visuais, verbais e sonoros ali incluídos. As fotografias mostram faces em zoom, muitas vezes em movimento, expressando a intensidade e fugacidade do momento do "transe carnavalesco", como afirma Omar (2005a), sob o qual a imagem foi capturada. Tal ideia é potencializada com aforismos que povoam o jogo. São frases enigmáticas que aparecem cada vez que o jogador forma um par de imagens e que se destacam quando o jogador conclui uma fase do jogo. Exemplos de aforismo são: "Não te vejo com a Pupila, mas com o Branco dos Olhos", "Contemplar é um Ato Violento" e, ainda, "Em Arte, jogamos sempre com o Acaso e 
com a Ordem". São frases que problematizam os atos de ver e de produzir imagem, explicitando a continuidade entre eles. Como é dito na abertura do jogo, os aforismos são "koans de sabedoria fotográfica".

Revelador é o fato de o próprio Omar ser coautor desse jogo digital, de modo que o jogo se apresenta tanto como obra quanto como metatexto. Como declarou Omar (2005a), levar uma obra para a web não é apenas digitalizá-la e publicá-la, é necessário tomá-la como "material", fazê-la voltar ao "estado puro" - a imagem - para, então, ser reunida numa nova forma. Isso é possível porque, para Omar, a imagem de uma obra tem possibilidades infinitas de regeneração.

Ao optar pela interface de jogo digital, Omar (2005b) problematiza a crença de que o enunciado direto sobre algo é a melhor forma de dar esse algo a conhecer - problematização que está na base da própria atividade artística. Para ele, o melhor modo de proporcionar ao público a fruição de suas "faces gloriosas" foi evitar reproduzir a estrutura original da obra, deixá-la em reserva, apresentando o conteúdo reestruturado na interface de jogo digital.

\section{Considerações finais}

A reciclagem dos modos de fazer, perceber e conhecer a obra de arte não é prática nova. O surgimento dos modernos museus de arte desde o final dos Setecentos, por exemplo, gerou um conjunto de valores e hábitos em relação à arte que não existia antes. Como disse Goethe, vivendo o contexto histórico de fundação do Louvre: o museu inaugurou uma "nova entidade artística", de modo que até a arte historicamente anterior tornou-se algo totalmente novo e aquilo que dela fora removido permanecerá um mistério para as gerações futuras (CRIMP, 2005). Goethe foi perspicaz. Hoje é difícil supor que entendimento teríamos de arte se as obras sacras continuassem nas igrejas e conventos, se a arte da corte não tivesse sido aberta ao público, se as pinturas de gênero continuassem em coleções privadas, se não fosse possível percorrer "toda" a tradição artística ocidental num único espaço. Sem espaços como o Louvre, Manet não teria dialogado com a "arte de museu" e Hélio Oiticica teria pouco a contestar sobre os mecanismos de legitimação da arte.

Museu de arte também é instituição social e, enquanto tal, é reciclável. Desde seu advento os museus de arte passaram por momentos de redefinição de modelos e práticas, vivendo 
um quase contínuo processo de transformação. A história da interface "sala expositiva" é exemplo disso. A primeira versão se desdobrou em diferentes abordagens que convivem na atualidade: paredes abarrotadas de quadros do mesmo período histórico; a estética clean do "cubo branco"; paredes terrosas para apresentar pinturas barrocas no intuito de recriar a luminosidade dos interiores do século XVII; a instalação de obras da arte contemporânea em salas que expõe quadros (obras da tradição de pintura de representação) para promover diálogo poético e supratemporal; entre outras abordagens. Sem diminuir o caráter inovador e louvável dessas iniciativas, a posição do espectador pouco se altera nelas.

Museus vêm criando dispositivos de deslocamento de seus visitantes para além da posição de espectador, pluralizando as formas de comunicar o acervo. As interfaces interativas, como as comentadas neste ensaio, são exemplo disso. Mas vale destacar: dispositivos interativos não dependem do uso de tecnologia digital. Interativa e não contemplativa é a experiência de passar uma tarde no museu dançando a partir de dada obra do acervo; ou passar uma noite no museu para investigar uma trama criada pelos educadores da instituição. Tais exemplos evidenciam o papel coautoral do espectador e as infindáveis possibilidades de leitura das peças do acervo. Também faz ecoar a ideia de museu plural de Martín-Barbero, evocada no início deste texto. Por essa via, o museu mostra-se como espaço de diálogo, deixa cair sua máscara de "caixa forte” da tradição. Impulsiona a transformação de hábitos e valores, injeta vitalidade na arte e na própria instituição museal. Até porque, como colocou Hans Belting, “[...] é uma questão de instituições e não de conteúdo, e muito menos de método, se e como arte e história da arte sobreviverão no futuro" (2006, p. 167).

\section{NOTAS}

1. Transcodificação é um dos cinco axiomas propostos por Manovich para pensar a linguagem dos novos meios. As outras quatro são: Representação numérica, Modulação, Automatização e Variabilidade.

2. Barthes diferenciou dois tipos de leitura: a) a leitura do prazer revela significados. Quanto mais erudito for quem pratica este tipo de leitura, mais prazer sentirá; b) a leitura praticada por aquele que deseja o texto e toma-o como espaço para o jogo da fruição não traz apenas prazer; provoca descontentamento ao não aportar um significado certeiro. Ela suscita o envolvimento do leitor, o qual logo se esvai no texto. A fruição faz o leitor entrar em crise e produzir um excesso de texto à maneira do texto desejado. É por isso que não há incoerência em fruir o texto em profundidade e, ao mesmo tempo, em dispersão. O leitor de fruição vive o prazer da escritura. O problema, reporta Barthes, é que em nossa "sociedade de consumo" o leitor de fruição vive na clandestinidade, contido na promessa de produção. 


\section{Referências}

BAHIA, Ana Beatriz. Jogando Arte na Web: Educação em Museus Virtuais. 2008. Tese (Doutorado em Educação) Centro de Ciências da Educação, Universidade Federal de Santa Catarina, Florianópolis, 2008.

BAHIA, Ana Beatriz. Do quadro ao jogo de fruição: Bosch Adventure Game. In: Revista Palíndromo, v. 6, n. 12. Florianópolis: UDESC, 2014.

BAHIA, Ana Beatriz. Museu e Web: arquivos de obras de arte. In XVI Encontro da ANPAP, Florianópolis: UDESC, 2007.

BARTHES, Roland. O prazer do texto. 4. ed. São Paulo: Perspectiva, 1996.

. O rumor da língua. 2. ed. São Paulo: Martins Fontes, 2004.

BELTING, Hans. O fim da história da arte: uma revisão dez anos depois. São Paulo: Cosac \& Naify, 2006.

CHAGAS, Mário. Apresentação. In: (Org.). Revista do Patrimônio Histórico e Artístico Nacional - Museus: Antropofagia da memória e do patrimônio, Brasília, n. 31, 2005.

CRIMP, Douglas. Sobre as ruínas do museu. São Paulo: Martins Fontes, 2005.

FRASCA, Gonzalo. Simulation 101: Simulation versus Representation (publicado em 2001). In: Ludology.org. Disponível em: < http://www.ludology.org/articles/simı/ simulation1o1.html>. Acesso em: 24 jul. 2015

FREIRE, Cristina. Poéticas do processo: Arte Conceitual no museu. São Paulo: Iluminuras \& MAC-USP, 1999.

MANOVICH, Lev. El lenguaje de los nuevos médios de comunicación: la imagen en la era digital. Buenos Aires: Paidós, 2006.

MARTIN-BARBERO, Jésus. Dislocaciones del tiempo y nuevas topografias de la memória. In: HOLANDA, Heloisa Buarque; RESENDE, Beatriz (Org.). Artelatina: cultura, globalização e identidade cosmopolita. Rio de Janeiro: Aeroplano e MAM-RJ, 2000.

; REY, Germán. Os exercícios do ver: hegemonia audiovisual e ficção televisiva. 2. ed. São Paulo: Senac, 2004.

OMAR, Arthur. Folha de São Paulo (entrevista concedida a Adriana Lift), São Paulo, jun. 1999. Disponível em: <http://www.museuvirtual.com.br/targets/galleries/ targets/mvab/targets /arthuromar/targets/entrevistas/ 
languages/portuguese/html/entrevistaarteeweb.html>. Acesso em: 22 mar. 2005a.

. Entrevista de Arthur Omar para Guiomar Ramos sobre o anti-documentário em Congo (1972) e O Anno de 1798 (1975) (transcrição de entrevista), out. 1993. Disponível em: <http://www.museuvirtual.com.br/targets/ galleries/targets/mvab/targets/arthuromar/targets/entrevistas/languages/portuguese/html/sobreoantidocumentario.html>. Acesso em: 22 mar. 2005b.

V2_ARCHIVE. Jheronimus Bosch internet game. Disponível em: <http://framework. v2.nl/archive/archive/node/work/ default.xslt/nodenr-124875>. Acesso em: 15 ago. 2006.

WILL, Chris. Entrevista concedida no Museu Boijmans Van Beuningen, Roterdan, 27 nov. 2006. Notas.

Recebido em: 06/02/15

Aceito em: 30/03/15

\section{ANA BEATRIZ BAHIA}

bahia@casthalia.com.br

Doutora em Educação (UFSC, 2008) e Bacharel em Artes Plásticas (UDESC, 1998). Em 200o, fundou o estúdio Casthalia, junto ao qual realiza criação, produção e implantação de tecnologias educacionais, em especial, jogos digitais para contextos de educação não formal. Também integra a equipe de produção de materiais didáticos do Centro de Referência e Formação em $\mathrm{EaD} / \mathrm{IFSC}$, atua como docente (UNISUL) e é membro do grupo de pesquisa ÁQIS (Centro de Artes/UDESC). É autora de jogos recomendados pelo MEC (via Guia de Tecnologias Educacionais), incluindo A mansão de Quelícera, voltado ao Ensino de Arte. Possui artigos acadêmicos publicados em livros e em anais de eventos nacionais e internacionais. Pesquisa a relação entre Artes, Educação e Tecnologias Digitais. 